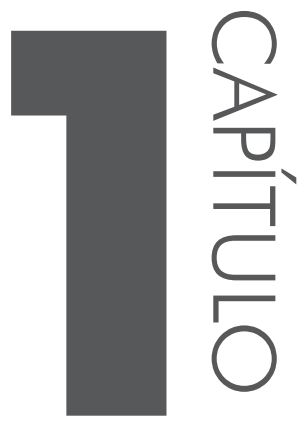

\title{
A CIDADE CONTEMPORÂNEA E O PAPEL DO PROGRAMA MINHA CASA, MINHA VIDA NO CONTEXTO DA HABITAC̣ÃO SOCIAL
}

Paulo César Pereira Matos José Henrique Rodrigues Stacciarini

Resumo: Na cidade contemporânea, o espaço é apropriado pelos mais diferentes grupos, com objetivos díspares e transformado em prol de necessidades momentâneas, o que contribui para a produção de um espaço urbano em processo contínuo de transformação e para a formação de uma cidade cada vez mais desigual devido aos diversificados usos do solo urbano, os quais têm como principal característica a propriedade privada. Devido a estas desigualdades, diversos são os conflitos e um deles é a busca, pelas classes de baixa renda, pelo direito à moradia, e é nesse sentido que o Estado, por meio das políticas habitacionais de 
interesse social, busca "amenizar" tais conflitos. O presente trabalho tem por objetivo apresentar algumas reflexões acerca da produção e reprodução do espaço urbano na cidade capitalista e dos condicionantes da atual política habitacional de interesse social voltada às classes de menor poder aquisitivo, a qual nos dias atuais tem como referência, em âmbito nacional, o programa Minha Casa, Minha Vida. Na construção deste, utiliza-se de pesquisa teórica de autores de grande relevância para a temática como também para a Geografia Urbana. Utiliza-se ainda pesquisadores que nos dão uma base sólida acerca das políticas públicas habitacionais de interesse social no Brasil.

Palavras-chave: Espaço urbano. Propriedade privada. Política habitacional. Minha Casa, Minha Vida.

Abstract: In the contemporary city, the area is suitable for the most different groups with disparate goals and made for the sake of momentary needs, thus contributing to the production of urban space in continuous transformation process and the formation of a city increasingly unequal due the diverse uses of urban land, the main feature private ownership of it. Because of these inequalities, many are conflicts and one of them is to search, by low-income classes, the right to housing and is in this sense that the state through the housing policy of social interest search "soften" such conflicts. This paper aims to present some reflections on the production and reproduction of urban space in the capitalist city and the constraints of current housing policy of social interest aimed at the lower income classes, which nowadays is referenced at the national level, the program Minha Casa, Minha Vida. In building this, it makes use of theoretical research on highly relevant authors to the theme as well as for Urban Geography. It is used yet, researchers who give us a solid foundation about the housing policies of social interest in Brazil.

Keywords: Urban space. Private property. Housing policy. Minha Casa, Minha Vida.

\section{INTRODUÇÃO}

Atualmente, o debate sobre a cidade e as questões urbanas possui uma vasta gama de produção científica e literária que contribui de forma efetiva para o entendimento e a compreensão acerca de diversas problemáticas inerentes ao processo de produção e reprodução do espaço urbano e à luta constante pelo direito à moradia realizada pelas classes sociais de menor poder aquisitivo. Neste sentido, faz-se necessário apresentar algumas reflexões conceituais básicas, que alimentam o arcabouço teórico da pesquisa que está sendo desenvolvida no Programa de Pós-graduação em Geografia da Regional Catalão, onde se utilizam tanto autores clássicos e contemporâneos da ciência geográfica bem como autores 
de outras ciências humanas que proporcionam uma base sólida para a discussão ora apresentada.

A habitação constitui-se de um direito e de um produto essencial na reprodução da vida humana. É uma necessidade básica a partir da qual pode-se notar que as técnicas de produção e construção das moradias foram se aprimorando com o avanço das forças produtivas, fato que remonta às aldeias das comunidades na pré-história e chega até os dias atuais em que são encontrados diversos tipos de moradias "ocupadas" de acordo com o padrão de consumo de cada sujeito e/ou família.

Trata-se a habitação como o espaço a ser ocupado antes e após a jornada de trabalho, a qual tem como função satisfazer as necessidades básicas do trabalhador, como: alimentação, descanso, lazer, atividades fisiológicas, entre outras. No entanto, para morar é necessário obter determinado valor monetário que irá definir a qualidade física (edificação) da moradia e também sua localização geográfica no sítio urbano da cidade, considerando a propriedade privada do solo urbano.

Tal fator torna-se excludente para com os "trabalhadores de baixa renda" que, por sua vez, encontram como alternativa para o problema da moradia as políticas públicas voltadas à produção de habitações de interesse social que se materializa em programas fomentados pelo Estado para suprir tal necessidade. Entretanto, tais políticas, com o discurso de garantir a inserção social destas famílias, acabam, por vezes, contribuindo para a segregação social das mesmas devido à construção conjuntos habitacionais em regiões periféricas e com pouca ou nenhuma infraestrutura para esses novos moradores.

Diante de tais considerações, busca-se construir uma discussão acerca da produção e reprodução do espaço urbano, utilizando autores como Carlos (1990, 2008), Santos (2004, 2009, 2014), Maricato (2001), Arantes et al (2000), Harvey (1980, 2005), Corrêa (1989), Rolnik (1995), Singer (1973), entre outros. Já adentrando a discussão acerca da problemática da moradia no Brasil, buscando compreender como se deu essa política em décadas passadas e já estabelecendo um elo com a atual política habitacional de interesse social, trabalha-se com os autores Araújo (2005), Maricato (2001, 1997), Engels (2015), Rodrigues (1989), Nunes (2014), Mioto (2015), Amore et al (2015). É válido ressaltar que, além destes autores, ao longo da pesquisa, são incorporados diversos outros, os quais por meio de seus trabalhos contribuem para a discussão ora brevemente apresentada.

A partir das leituras e pesquisas realizadas, entende-se que a cidade contemporânea, em sua estrutura urbana, dotada de prédios, ruas, avenidas, casas, indústrias passou e passa por diversas modificações no decorrer dos períodos históricos e das transformações do modo de produção vigente. O espaço urbano, na cidade contemporânea, é produzido e reproduzido em prol de necessidades individuais e também coletivas dos atores sociais que estão inseridos na lógica 
de reprodução do capital, o que consolida uma cidade cada vez mais dotada de particularidades.

Tais desigualdades se manifestam no cenário urbano de diversas maneiras, portanto, será ressaltada, no presente texto, a segregação residencial ocorrida a partir da propriedade privada do solo urbano, onde se faz necessário possuir determinado valor monetário para adquirir uma parcela dele. Em meio a isto, as políticas públicas voltadas à provisão de habitação para as classes sociais de menor renda surgem como uma alternativa de moradia, e atualmente, em âmbito nacional, há o Programa Minha Casa, Minha Vida, que visa atender essa demanda social.

\section{A PRODUC̣ÃO E A REPRODUČÃO DO ESPAC̣O URBANO: ALGUMAS REFLEXỐES TEÓRICAS}

É notória, nas cidades atuais, uma diversificada gama de conflitos de interesses: a luta por infraestruturas básicas, como saneamento e transporte, a disputa por espaços de interesse do capital e de alguns estratos da sociedade, assim como a luta pelo direito de moradia entre as classes de menor poder aquisitivo e o Estado. No entanto, alguns condicionantes contribuem para a manutenção destes conflitos que citamos anteriormente, tal como a reprodução do capital e a apropriação do solo urbano por diversos atores sociais e/ou agentes, que, por sua vez, possuem interesses e objetivos dispares.

Neste sentido, podemos aferir que o espaço urbano da cidade capitalista é dotado de contradições e conflitos de interesse entre o capital e o social que contribuem para a produção e a reprodução do urbano e transformam a terra urbana em uma mercadoria dotada de valor de uso e de troca.

Ao nos referirmos ao processo de produção e reprodução do espaço urbano, constata-se, a partir da literatura pesquisada, tratar-se de dois momentos distintos, porém interligados, que estão ainda diretamente ligados à reprodução da vida humana. Sobre o processo de produção, Carlos (2008) nos diz que ele se refere ao processo específico e o concebe como sendo condição, meio e produto; já o segundo (reprodução) considera a acumulação do capital por meio de sua reprodução, permitindo apreender a divisão do trabalho em seu movimento. A reprodução do espaço só é possível a partir do momento em que ele já foi produzido pelo trabalho do homem, ou seja, a consolidação do processo de produção, de circulação, de distribuição e de troca.

Emerge, então, a concepção de que o processo de produção se alicerça na reprodução das relações sociais por meio de sua materialização em determinados momentos da história da sociedade, regidos por um modo de produção vigorante que, no caso da sociedade contemporânea, baseia-se nas relações capitalis- 
tas. Neste sentido, considera-se que o espaço é produzido devido às necessidades humanas em diferentes momentos históricos.

Assim, o processo de produção do espaço perpassa ainda o de reprodução do capital, e por esta condição, é constituída uma série de relações - sociais, jurídicas, econômicas, políticas e também culturais - das quais surgirá o já mencionado espaço urbano.

Destaca-se que a função do espaço é permitir o desenvolvimento dos processos de produção, sendo eles: distribuição, circulação e troca. Por meio do consumo, que se dá em lugares e em tempos diferentes, a atividade produtora se liga às demais e consolida as relações citadas anteriormente. Para Corrêa (2011), a produção do espaço é consequência da ação de agentes sociais concretos, históricos, dotados de interesses, estratégias e práticas espaciais próprias, portadores de contradições e geradores de conflitos entre eles mesmos e outros segmentos da sociedade.

Como condição primordial na produção do capital e reprodução da sociedade, tem-se a apropriação do solo urbano, o qual, na lógica do modo de produção capitalista, está impregnado pela ideia de propriedade privada do solo que proporciona renda e é usado diferentemente pelos mais variados grupos sociais e econômicos. Com esta apropriação, será construída uma série de relações e também de conflitos.

Atentemos, então, para a ideia do espaço como mercadoria que possui, assim, um valor específico no que tange à sua ocupação, o qual deve ser pago para se ter direito de usufruir dos benefícios do espaço. Ao tratarmos o espaço urbano como mercadoria, automaticamente, pode-se incorporar ainda o valor de uso e o valor de troca, sendo que terá valor de uso a partir do momento que surgem necessidades sociais, como hábitos culturais, lazer e estilos de vida díspares.

O valor de uso, é, portanto, condição necessária à produção de mercadorias e à reprodução da força de trabalho, ou seja, local onde o trabalhador irá construir sua moradia e constituir suas relações cotidianas com o lugar. Carlos (2011) pondera ainda sobre os valores de uso e troca:

O espaço-mercadoria se propõe para a sociedade como valor de troca, destituído de seu valor de uso e, nessa condição, subjugando o uso, que é condição e meio da realização da vida social, às necessidades da reprodução da acumulação como imposição para a reprodução social. É nesse processo que o valor de troca ganha uma amplitude profunda - o que pode ser constatado pela produção dos simulacros espaciais como decorrência de revitalizações urbanas (CARLOS, 2011, p. 61).

Ainda neste sentido, como apontado pela autora supracitada, utilizamo-nos das palavras de Singer (1982, p. 33) quando aponta que "a propriedade privada 
do solo urbano faz com que a posse da renda monetária seja requisito indispensável à ocupação do espaço urbano" e a partir disto ocorre uma exclusão do direito de propriedade dos sujeitos que não possuem renda monetária suficiente para ter acesso à parcela do solo urbano destinado à construção de moradia própria.

De acordo com o que foi exposto, e buscando avançar na discussão, classifica-se a utilização do solo urbano em três vertentes: pelo uso industrial e comercial, pelo uso residencial e de lazer e também pelos usos públicos comuns a todos os moradores, independente de posição social. Do lado das empresas (detentores do capital), a apropriação do solo urbano dá-se objetivando extrair lucro com a sua ocupação ao realizar atividades produtivas (atividades secundárias e terciárias) ou atividades de circulação comercial, financeira.

Já no que diz respeito ao morador, este busca ocupar uma parcela do solo urbano no intento de estabelecer um local para moradia, seja por meio da compra e/ou do aluguel, chegando até, em determinados casos, à ocupação ilegal por não ter condições de pagar por determinada parcela do solo urbano. O solo urbano de uso coletivo dá-se com apropriação de determinada parcela do espaço pelo Estado visando à construção de bens que são de interesse de todos os moradores da cidade, independentemente de sua posição social. Logicamente, em alguns casos, uma classe terá mais privilégios que outras no que tange ao acesso e à utilização de tais bens de consumo coletivo.

Singer (1982) explica ainda que há diversas formas de extrair renda da terra urbana com apropriação do solo pelos detentores de capital (empresas, indústrias, estabelecimentos comerciais) devido a sua localização e também a sua função e/ou produção baseada na concepção de que todo espaço urbano é propriedade privada - salvo algumas exceções - em que, necessariamente, paga-se pelo uso, seja por meio da compra ou do aluguel. Essa propriedade privada do solo urbano é responsável pela exclusão do direito de propriedade do solo, a qual, por sua vez, é criada dentro das contradições da cidade capitalista, que produz ainda áreas de segregação residencial e social, inerentes à distribuição de renda gerada no processo de reprodução do capital refletindo espacialmente. Corrêa (2013) vê a segregação residencial como responsável pela fragmentação do espaço urbano ao criar inúmeras áreas sociais diferentes umas das outras, mas que, por um ou outro motivo, mantêm-se interligadas.

No contexto da habitação, há também formas de extração de lucro por meio da venda de imóveis voltados principalmente à classe mais rica, que possui recursos disponíveis para adquirir sua moradia em empreendimentos lançados por promotores imobiliários em locais que possuem uma gama maior de atrativos e que, por vezes distante do centro operacional, possui certas particularidades e amenidades não encontradas em determinadas partes da cidade, como se pode ver nos novos condomínios fechados, facilmente encontrados na cidade contemporânea. 
Outra forma de se agregar valor a determinada parcela do solo urbano destinada à moradia são as facilidades de acesso a infraestrutura, como centros comerciais, lazer etc., e os bens de consumo coletivo - escolas, creches, hospitais, praças etc. Há, no entanto, um agravante no que diz respeito à infraestrutura no local da moradia (água, esgoto, asfalto, hospitais etc.), o qual se dá no fato de que quando o Estado constrói serviços urbanos em determinado bairro, o valor dos imóveis nestes locais aumenta automaticamente devido à valorização do terreno pelas novas infraestruturas, o qual, por vezes, é apropriado pelo capital imobiliário. Como própria condição presente no capitalismo, a renda monetária faz com que o espaço na cidade seja limitado pela sua disposição. Essa diferenciação propiciada pela renda monetária é ressaltada por Rodrigues (2013), que acrescenta ainda que "para morar é necessário ter capacidade de pagar por esta mercadoria não fracionável, que compreende a terra e a edificação, cujo preço depende também da localização em relação aos equipamentos coletivos e à infraestrutura existente nas proximidades da casa/terreno" (RODRIGUES, 2013, p. 14).

No entanto, como já mencionado anteriormente, devido à propriedade privada do solo urbano, ocorre a exclusão do direito de propriedade das classes sociais de menor renda. E, a partir disto, para as classes de baixa renda, como uma das alternativas de moradia resta a construção de habitações, por vezes, em locais ilegais, marcados pela autoconstrução.

Verifica-se, também, como alternativa de moradia para a população de baixa renda, que não consegue ter acesso a uma parcela do solo urbano, os programas habitacionais de interesse social. Como principal responsável pela criação de programas que vão ao encontro das famílias de baixa renda, tem-se o agente Estado. De acordo com Harvey (2005, p. 79), "há pouquíssimos aspectos da produção e do consumo que não estão profundamente afetados, direta ou indiretamente por políticas" deste agente. Fica ainda a cargo do Estado a mediação dos conflitos ao longo do processo de reprodução do capital. Sua associação com o capital privado dá origem, no cenário urbano, a áreas de segregação, principalmente no que se refere à questão da habitação.

Contextualizando o que foi exposto até o presente momento, afere-se que a reprodução do espaço urbano e a produção da cidade, juntamente com as relações capitalistas, são responsáveis pelas desigualdades sociais e diferenciação entre as classes. Com isto, a moradia aparece como uma mercadoria inestimável e imprescindível ao homem para que ele se estabeleça como sujeito participante da sociedade. A questão da moradia permeia ainda várias discussões acerca da busca pelo direito à cidade e se apresenta também na sociedade contemporânea como objeto de luta pelas classes de trabalhadores assalariados que, por sua vez, constituem-se como a base do modo de produção capitalista ao venderem a sua força de trabalho. Para essa classe trabalhadora, a habitação toma fundamental 
importância, pois, como aponta Abiko (1995, p. 20), “a habitação é o espaço ocupado pela população após e antes do enfrentamento de uma nova jornada de trabalho, desempenhando ali algumas tarefas primárias como alimentação, descanso, atividades fisiológicas, convívio social. Além do desenvolvimento destas tarefas, a habitação é o espaço no qual muitas vezes ocorre, em determinadas situações, atividades de trabalho".

Sendo, então, a habitação um bem para o sujeito (homem) e uma mercadoria no modo capitalista de produção, o qual no bojo das relações instituídas torna-se alvo de disputas pelas classes sociais mais pobres, que buscam o seu direito de morar em uma sociedade em que, claramente, está presente o objetivo da acumulação da capital a qualquer custo: pelos mercados imobiliários cada vez mais especulativos, pelos baixos salários que, frequentemente, não dão uma boa qualidade de vida e geram assim uma série de outras questões. Uma das maneiras de lutar pelo direito à habitação, como já foi ressaltado ao longo do texto, são as políticas públicas e/ou programas fomentados pelo Estado para "facilitar" o acesso da classe trabalhadora de baixa renda à casa própria - o que, atualmente, se faz pelo programa Minha Casa, Minha Vida que será abordado no próximo tópico.

\section{PROGRAMA MINHA CASA, MINHA VIDA (MCMV) NO ATUAL CONTEXTO DA HABITAC̣ÃO POPULAR NO BRASIL}

Antes de adentrarmos a discussão acerca do programa Minha Casa, Minha Vida, é importante que façamos uma breve contextualização acerca da política habitacional no país, que teve uma atuação mais incisiva a partir da década de 1930. Tais políticas visam ao atendimento de uma demanda social constituída no seio de um sistema que tem, dentro de sua lógica de reprodução, a desigualdade social como marco, e por isso, criam-se cidades cada vez mais excludentes para as camadas sociais de baixa renda.

De acordo com os estudos de Azevedo e Andrade (1987), Maricato (1982) e como apontado também nas pesquisas de Triana Filho (2006), a política habitacional de interesse social no país quase inexistiu até meados da década de 1930. O Estado passou a atuar de forma mais efetiva, porém, com ações mais discretas, no que diz respeito à política habitacional de interesse social, no período denominado Estado Novo que compreende os anos de 1937 a 1945 com o IAPs (Institutos de Aposentadoria e Pensão), considerado, como aponta Triana Filho (2006), o precursor da política habitacional no país voltada às classes de menor renda.

No contexto nacional, é possível elencar, de maneira sucinta, três períodos que marcam efetivamente a política habitacional de interesse social no Brasil, não deixando de considerar os Institutos de Aposentadoria e Pensão (IAPs) citados 
anteriormente, sendo respectivamente a Fundação Casa Popular (FCP) criada em 1946 que advém da ideia inicialmente cunhada com os IAPs. Posteriormente, surge o Banco Nacional de Habitação (BNH), criado em 1964 com as conhecidas Companhias de Habitação (COHABs) para suprir as falhas da antiga Fundação Casa Popular (FCP) com as conhecidas Companhias Habitacionais (COHABs) e, no atual momento, há o programa Minha Casa, Minha Vida.

Os dois períodos iniciais citados, a Fundação Casa Popular (FCP) e o Banco Nacional de Habitação (BNH), marcados por suas peculiaridades e também pelo momento econômico e social em que o Brasil se encontrava, compreendidos nas décadas de 1945 a 1980, não conseguiram expressivos números, como pode ser visto nos trabalhos de Maricato (1982) e de Triana Filho (2006), no que tange a produção de habitações para as camadas mais pobres. Como uma das características presentes em tais conjuntos, observado a partir dos estudos realizados para a construção do presente trabalho, nota-se que as moradias eram produzidas, não diferentemente da atualidade, em larga escala e em locais periféricos, sem o mínimo de infraestrutura (rede de água, esgoto, asfaltamento nas ruas). Uma figura que ganha espaço dentro de tais políticas, sagrando-se mais efetivamente no Banco Nacional de Habitação (BNH), são as empresas de capital privado que ficam responsáveis pela produção das habitações.

Após o período de vigência dos dois programas, encerrado no ano de 1986, a Caixa Econômica Federal (CEF) torna-se o principal agente responsável pelo provimento e execução de políticas de habitação, saneamento e desenvolvimento urbano no país. Além da Caixa Econômica Federal (CEF), os municípios e estados ficaram responsáveis por fomentar políticas para atender às demandas sociais de moradia, como é o caso das Vilas Mutirão, muito comuns no estado de Goiás, entre as décadas de 1980 e de 1990.

Do ano 2000 em diante, são criados alguns órgãos com o intuito de fomentar o desenvolvimento urbano e também contemplar a produção de moradia para as classes sociais mais pobres. Dentre estes órgãos, cita-se o Ministério das Cidades, criado em 2003, que passa a ser responsável pelo gerenciamento de políticas e planos no que diz respeito à política urbana como um todo. Cria-se, em 2005, o Sistema Nacional de Habitação de Interesse Social (SNHIS) e o Fundo Nacional de Habitação de Interesse Social (FNHIS). O objetivo do SNHIS é implantar políticas e programas para a promoção de acesso à "moradia digna" por parte das famílias de baixa renda e, por sua vez, o FNHIS faz o gerenciamento dos recursos que são destinados à habitação de interesse social.

No bojo destas políticas e órgãos que são criados a partir do ano 2000, é idealizado pelo Estado o programa Minha Casa, Minha Vida, criado em 2009 por meio da Lei n. 11.977, no governo do então presidente Luís Inácio Lula da Silva. Além deste programa, que se apresenta como referência na produção de ha- 
bitações de interesse social no Brasil como um todo, há os programas criados nos estados e municípios com as particularidades de cada uma destas esferas político-administrativas. O programa é coordenado diretamente pela Caixa Econômica Federal (CEF), tem provisão de recursos do Fundo de Arrendamento Residencial (FAR) e o capital privado como agente construtor de tais habitações.

Porém, o programa foi criado dentro de uma série de medidas fomentadas pelo Governo e denominada Programa de Aceleração do Crescimento (PAC), sancionado em 2007, que objetivava desenvolver e impulsionar diversos setores da economia no país por meio de investimentos bilionários. Assim, em 2009, a criação do Minha Casa, Minha Vida, objetivava construir moradias para famílias que possuíssem renda de até três salários mínimos e posteriormente para as famílias que recebessem até dez salários, além de e aquecer a economia ao abrir novos postos de trabalho no ramo da construção civil, em que empresas de capital privado são responsáveis pela edificação dos empreendimentos.

A meta inicial do Minha Casa, Minha Vida era a construção em âmbito nacional de um milhão de moradias, mas posteriormente foi modificada para três milhões de moradias na forma de conjuntos horizontais e verticais abrangendo famílias que possuem renda mensal de até dez salários. Visando alcançar tal objetivo, o programa foi dividido em duas fases: o Minha Casa, Minha Vida fase 1 e fase 2, mudando apenas algumas regras para financiamento a fim de que possa abarcar um maior quantitativo de famílias que possuem renda mensal de até 1.600 reais.

No que se refere à operacionalização do programa, mais especificamente sobre as modalidades de financiamento, estas são divididas entre faixas salariais, como já foi abordado anteriormente. Tais modalidades se dividem em três grupos: o P1, para famílias que recebem até três salários, o P2, para famílias que recebem de três a seis salários, e o P3, que abrange famílias de seis a dez salários. Nosso enfoque, porém, está no chamado P1, que compreende as classes de baixa renda. Nesta modalidade, a construção das habitações se dá com recursos do Fundo de Arrendamento Residencial (FAR) em parceria com a CEF e empresas de capital privado no ramo da construção civil. O público-alvo do Minha Casa, Minha Vida, inicialmente, são as famílias que recebem até três salários de renda mensal e possuem acesso ao subsídio integral no ato do financiamento da casa própria, pois as parcelas são reduzidas e não podem ultrapassar $10 \%$ da renda bruta familiar.

Atualmente a problemática da moradia é um dos principais pontos de debate, pois envolve questões que não perpassam apenas a construção física das unidades habitacionais. Perpassam também fatores que envolvem a estrutura de renda das classes sociais menos abastadas, beneficiárias destes programas, bem como a dificuldade de acesso aos financiamentos pelo atual programa Minha 
Casa Minha Vida. Há de se acrescentar ainda a forma (estrutura física) pela qual se dá a produção destas unidades habitacionais por parte do capital privado, que busca garantir maior lucratividade neste processo. Em meio a este debate, Abiko (1995, p. 12) nos lembra que:

A habitação popular não deve ser entendida meramente como um produto e sim como um processo, com uma dimensão física, mas também como resultado de um processo complexo de produção com determinantes políticos, sociais, econômicos, jurídicos, ecológicos, tecnológicos. Este entendimento é fundamental se quisermos perseguir a solução do problema habitacional com todas as suas dificuldades e condições de contorno.

A habitação, então, não é somente o produto “vendido" pelo capital privado e financiado pelo Estado, que será destinado de maneira genérica ao homem, mas deve ser encarada como uma forma de inserção social das populações menos assistidas e que historicamente vivem à margem da sociedade. As políticas habitacionais devem atender em sua totalidade as necessidades presentes no cotidiano dos moradores destes conjuntos habitacionais que são criados a partir de programas como o Minha Casa, Minha Vida.

Outro fator de grande repercussão e debate, no que tange a produção física destas habitações por tais programas, diz respeito à própria estrutura física destas habitações, que deve contemplar também toda a infraestrutura básica (escolas, água, esgoto, postos de saúde) necessária para a reprodução da vida humana, pois, além de oferecer a construção física da moradia, é necessário oferecer as condições mínimas para que tais famílias possam ocupar de forma satisfatória esse espaço. Azevedo e Andrade (1982) afirmam que tais programas habitacionais podem ser inviabilizados caso outras políticas urbanas, como as de transporte, energia elétrica, rede de água e esgoto, não estejam integradas.

Contudo, é neste cenário que se buscam analisar tanto a produção de habitações de interesse social de uma maneira geral pelo Minha Casa, Minha Vida quanto suas implicações, levando em consideração o artigo $6 .^{\circ}$ do Estatuto das Cidades, que diz: "são direitos sociais a educação, a saúde, o trabalho, a moradia, o lazer, a segurança, a previdência social, a proteção à maternidade e à infância, a assistência aos desamparados" (BRASIL, 2002, p. 10). É notória a importância do programa para o atendimento das classes de menor renda; no entanto, é preciso se discutir alguns aspectos que permeiam a produção física das habitações.

Mesmo com tais questionamentos e "problemas" no que tange a produção das habitações, destaca-se a importância do programa para os trabalhadores de baixa renda, pois, por intermédio do Minha Casa, Minha Vida, consegue-se ter acesso à moradia própria. No entanto, a questão não é apenas em produzir as habitações em qualquer espaço na cidade e de qualquer forma; é necessário que 
haja o mínimo de dignidade em tais habitações e no local e/ou bairro que estes estão localizados. Uma crítica a ser feita baseia-se no fato de se primar pela diminuição dos custos com a produção e pelo aumento do quantitativo de unidades por parte do capital privado e até mesmo do Estado, construindo-se prédios demasiado pequenos e em locais distantes do centro que possuem pouca ou nenhuma infraestrutura e equipamentos públicos necessários ao atendimento destes trabalhadores.

É notável que o capital privado, com a implantação do Minha Casa, Minha Vida, busca cada vez mais formas de lucrar. As grandes construções em massa de apartamentos de interesse social figuram como uma delas, pois o Estado desonera os custos de produção de gastos com o terreno e, em alguns casos, da própria compra do local em que serão edificadas as habitações, amparado em Catalão pela Lei $n^{\circ}$ 2.210/04 do Solo Urbano. Contribui-se para o modelo de cidade excludente ao segregar as classes de trabalhadores mais pobres em determinados locais da cidade, distantes, preferencialmente, de bairros e condomínios voltados às classes de maior poder aquisitivo.

Morar dignamente não é ter para uma família um apartamento de $42 \mathrm{~m}^{2}$. Morar dignamente é ter a oportunidade de crescimento enquanto sujeito social, mesmo que isto demande um esforço maior do Estado quando se trata da construção de conjuntos habitacionais horizontais. Mesmo que utilize de estratégia de barateamento na construção pela aquisição de terrenos distantes, deve-se oferecer nestes bairros as infraestruturas básicas e os equipamentos públicos necessários a uma boa qualidade de vida.

Ressalta-se, no atual contexto da política habitacional de interesse social, que a luta pela apropriação da cidade não se finda para o trabalhador de baixa renda no momento em que este é beneficiado por tal habitação. Pelo contrário, a luta passa a ser pelo direito à cidade e aos bens de consumo coletivos, que são de direito de todos independentemente de morarem em um bairro popular ou em um bairro de luxo. Diversos movimentos sociais urbanos vêm explicitando esta luta, concretizando-se como agentes que atuam em prol dos trabalhadores de baixa renda, como ocorre atualmente em São Paulo com o Movimento dos Trabalhadores Sem-Teto (MTST), que objetiva a conscientização da grande massa de trabalhadores (assalariados, de baixa renda, autônomos etc.) pela busca de melhores condições de vida na cidade e pelo direito à moradia digna. Tais movimentos são formas de resistência e de luta contra as desigualdades sociais emergentes no processo de reprodução do capital.

Destarte, o Minha Casa, Minha Vida favorece o aumento nos preços dos imóveis e valorização de glebas de terras em decorrência das "facilidades" de financiamento impostas por tal programa e figura como uma forma de atração para pretensos compradores de lotes ou moradias prontas. Os proprietários imo- 
biliários buscam, a partir destas novas "facilidades" de financiamento, alcançar as classes de rendas médias que se dispõem a pagar preços maiores por empreendimentos ou moradias - aquecendo, assim, o mercado imobiliário.

Fazendo uma breve análise, desde a criação do Minha Casa, Minha Vida até o presente momento, tal programa figura como uma das principais formas de acesso das classes menos abastadas financeiramente à moradia própria. Durante esse período, segundo boletim da CEF até junho de 2013, foram contratadas em todas as três linhas de financiamento 3.012.848 unidades, e entregues 1.405.710 habitações. Entretanto, esses números são gerais e não retratam a quantidade de habitações que foram contratadas e entregues para as classes consideradas de baixa renda incluídas na faixa de financiamento de um a três salários.

Comparando-se os números com os da Fundação Casa Popular (FCP) e os do Banco Nacional de Habitação (BNH), a produção de habitações pelo programa em menos de dez anos de criação supera os demais. Porém, não há como mensurar a real dimensão em qualidade de acesso às infraestruturas básicas nestes conjuntos habitacionais - os quais vêm se alastrando nas cidades brasileiras como um modelo padrão de conjuntos horizontais e, atualmente, de grandes conjuntos verticais - no que se refere a como estes beneficiários estão inseridos na dinâmica espacial das cidades. Por tais apontamentos, e buscando algumas reflexões preliminares acerca da atual conjuntura em que se dá a produção destas habitações, busca-se as reflexões de Harvey (2013, p. 33) quando o autor discorre que o direito à cidade

não é apenas um direito condicional de acesso àquilo que já existe, mas sim um direito ativo de fazer a cidade diferente, de formá-la mais de acordo com nossas necessidades coletivas (por assim dizer), definir uma maneira alternativa de simplesmente ser humano. Se nosso mundo urbano foi imaginado e feito, então ele pode ser reimaginado e refeito.

Esse direito à cidade mencionado pelo autor pode ser compreendido como o direito a uma cidade diferente, perpassando pela utopia de uma cidade que agregue todos os seus moradores, sem que haja uma divisão espacial excludente que segregue as classes de baixa renda. Buscando também outra forma de compreensão do que o autor ora citado coloca, no que se refere ao direito à cidade, faz-se necessário buscar refletir sobre tal programa habitacional em questão, pois a habitação figura como bem primordial para o ser humano, mas o espaço urbano da cidade não é pensado para as classes mais pobres que se utilizam destes programas habitacionais.

A cidade é pensada e transformada de acordo com as necessidades intrínsecas dos agentes sociais que se apropriam do espaço urbano com o único objetivo 
de mercantilizar o solo urbano. Neste sentido, não há o pensamento de garantir aos habitantes dos conjuntos situados em locais distantes o acesso de direito aos bens comuns a toda sociedade como educação, saúde, transporte de qualidade, lazer etc. Os rumos de tais programas, por vezes, vão ao encontro dos objetivos do capital privado por maximizar/obter lucro pela produção em massa de moradias, com custos reduzidos, sem considerar os direitos mínimos do trabalhador quanto à construção de sua vida nos locais onde são construídos os empreendimentos.

Algo a ser ponderado, para que se pense sobre a política habitacional proposta no Minha Casa, Minha Vida e sobre os novos financiamentos, diz respeito ao reforço da ideologia da casa própria já cunhada dentro do próprio Banco Nacional de Habitação (BNH), a qual se transforma em instrumento para a reprodução das relações capitalistas e para o controle social; pois, por meio destas novas construções, a indústria de construção civil se mantém aquecida junto ao mercado de terras e o imobiliário. Em consonância com a manutenção destas relações capitalistas que ditam as regras de onde e como morar, os trabalhadores de baixa renda que realmente necessitam ficam "reféns" de uma política que tem como discurso a inserção social das camadas de baixa renda, mas que por outro lado favorece o grande capital privado.

\section{CONCLUSÃO}

A partir das reflexões apresentadas no presente texto, afere-se que o espaço está sempre em processo de transformação e mutação, tendo como o principal sujeito o homem que, por suas ações em determinado processo de produção, modifica-o em decorrência de suas necessidades. $\mathrm{Na}$ contemporaneidade, em que o espaço está em constante processo de modificação devido à reprodução das relações capitalistas, a cidade surge como o processo contínuo de produção da sociedade em consonância com a reprodução das relações sociais.

No processo de produção e reprodução do espaço urbano, como colocado pelos autores no decorrer do texto, há a apropriação do solo urbano por diversos atores sociais e é a partir da propriedade privada do solo que se torna necessário despender de determinado valor monetário para se ter acesso a uma parcela deste. Por tal fator, serão "distribuídas" de forma heterogênea no espaço urbano, as diferentes classes sociais, visíveis em bairros operários e bairros de alto padrão. Há também diferenciação na distribuição dos serviços e das infraestruturas, os quais serão disponibilizados em maior ou menor abundância em decorrência da faixa de renda de determinada parcela da população.

Neste cenário urbano da cidade capitalista, há diversos conflitos no que diz respeito à apropriação deste espaço, pois para as classes de baixa renda restam como alternativas à moradia as ocupações ilegais e/ou a busca por bairros perifé- 
ricos com pouca ou nenhuma infraestrutura básica e os programas habitacionais de interesse social, como são os casos da mencionada Fundação Casa Popular (FCP), do Banco Nacional de Habitação (BNH) com as COHABs e do atual programa Minha Casa, Minha Vida responsável por prover a tais classes o acesso a moradia. Tais programas fomentados pelo Estado objetivam também a produção de habitações para estas classes de baixa renda.

Tal programa, o Minha Casa, Minha Vida, logicamente contribui, na atualidade, de forma positiva, para o acesso das classes de baixa renda à moradia; porém, há de se ressaltar que tal programa contribui, por outro lado, para a reprodução do capital por meio das parcerias entre o público e o privado na produção dos conjuntos habitacionais de interesse social.

Por fim, permeando tais reflexões, é importante ponderar que a discussão ora apresentada está longe de ser exaurida e apresenta-se como preliminares resultados e indagações a serem consolidadas no desenvolvimento da presente pesquisa sobre habitação de interesse social e sobre o atual programa Minha Casa, Minha Vida, a qual está em andamento no Programa de Pós-Graduação em Geografia pela UFG, Regional Catalão.

\section{REFERÊNCIAS}

ABIKO, A. K. Introdução à gestão habitacional. São Paulo: Edusp, 1995.

AMORE, C. S.; LÚCIA, Z. S.; MARIA, B. C. R. (Org.). Minha Casa... e a cidade?: avaliação do programa minha casa minha vida em seis estados brasileiros. Rio de Janeiro: Letra Capital, 2015.

ARAÚJO, M. S. de C. Os donos da casa: das políticas públicas de habitação aos significados da moradia. 2005. 168 f. Dissertação (Mestrado em Políticas Públicas e Sociedade) - Universidade Estadual do Ceará, Fortaleza, 2005.

ARANTES, O.; VAINER, C.; MARICATO, E. A cidade do pensamento único: desmanchando consensos. Petrópolis: Vozes, 2000.

AZEVEDO, S. de.; ANDRADE, L. A. G. de. Habitação e poder: da Fundação Casa Popular ao Banco Nacional de Habitação. Rio de Janeiro: Zahar, 1982.

. Desafios da habitação popular no Brasil: políticas recentes e tendências. Porto Alegre, 2007. (Coleção Habitare ANTAC).

BONDUKI, N. G. Origens da habitação social no Brasil. Análise social, v. 127, p. 711732, 1994. Disponível em: <http://analisesocial.ics.ul.pt/>. Acesso em: 10 mai. 2014.

BRASIL. Estatuto da cidade: Lei n ${ }^{\circ}$ 10.257, de 10 de julho de 2001, e legislação correlata [recurso eletrônico]. 4. ed. Brasília: Câmara dos Deputados, Edições Câmara, 2012.

CARLOS, A. F. A. A (re) produção do espaço urbano. São Paulo: Edusp, 2008.

. Espaço e indústria. 3. ed. São Paulo: Contexto, 1990.

CORRÊA, R. L. O espaço urbano. São Paulo: Ática, 1989. 
. Sobre agentes sociais, escala e produção do espaço: um texto para discussão. In: CARLOS, A. F. A.; SOUZA, M. L. de; SPOSITO, M. E. B. (Org.). A produção do espaço urbano: agentes processos, escalas e desafios. São Paulo: Contexto, 2011.

ENGELS, F. Sobre a questão da moradia. São Paulo: Boitempo, 2015.

HARVEY, D. A produção capitalista do espaço. São Paulo: Annablume, 2005. (Coleção Geografia e Adjacências).

A justiça social e a cidade. São Paulo: Hucitec, 1980.

- A liberdade da cidade. In: MARICATO, E. et al. Cidades rebeldes: passe livre e as manifestações que tomaram as ruas do Brasil. São Paulo: Boitempo; Carta Maior, 2013. LEFEBVRE, H. O direito à cidade. Tradução, prefácio e notas de Rubens Eduardo Frias. São Paulo: Centauro, 2001.

MARICATO, E. et al. Cidades rebeldes: passe livre e as manifestações que tomaram as ruas do Brasil. São Paulo: Boitempo, Carta Maior, 2013.

MARICATO, E. Brasil, cidades: alternativas para a crise urbana. Rio de Janeiro: Editora Vozes, 2001.

MARICATO, E. et al. (Org.). A produção capitalista da casa (e da cidade) no Brasil industrial. São Paulo: Alfa-Omega, 1982.

. Política habitacional no regime militar: do milagre brasileiro à crise econômica. Petrópolis: Vozes, 1987.

. Habitação e cidade. São Paulo: Atual, 1997.

MIOTO, B. T. As políticas habitacionais no subdesenvolvimento: os casos do Brasil, Colômbia, México e Venezuela (1980/2013). 2015. Tese (Doutorado) - Universidade Estadual de Campinas, Instituto de Economia, Campinas, 2015.

NUNES, L. M. dos S. Políticas públicas habitacionais e segregação socioespacial: o bairro Jardins Mangueiral na região administrativa de São Sebastião (DF). 2014. Dissertação (Mestrado) - Universidade Federal de Goiás, Departamento de Geografia, Catalão, 2014.

SANTOS, M. Espaço e método. 5. ed. São Paulo: Edusp, 2014.

Metamorfoses do espaço habitado. 6. ed. São Paulo: Edusp, 2014.

Pensando o espaço do homem. 5. ed. São Paulo: Edusp, 2004.

Pobreza urbana. São Paulo: Edusp, 2009.

SINGER, P. Economia política da urbanização. São Paulo: Brasiliense, 1973.

. O uso do solo urbano na economia capitalista. In: MARICATO, E. (Org.). A produção capitalista da casa (e da cidade) no Brasil industrial. São Paulo: Alfa-Ômega, 1982. RODRIGUES, A. M. Moradia nas cidades brasileiras. 10. ed. São Paulo: Contexto, 2013. ROLNIK, R. O que é cidade. São Paulo: Brasiliense, 1995.

TRIANA FILHO, A. Habitação popular no Brasil: análise do modelo operacional de financiamento pelas agências oficiais. 2006. 153 f. Dissertação (Mestrado) Universidade Federal de Brasília, Faculdade de Arquitetura e Urbanismo, Brasília, 2006. VASCONCELOS, P. de A.; CORRÊA, R. L.; PINTAUDI, S. M. (Org.). A cidade contemporânea: segregação espacial. São Paulo: Contexto, 2013. 